\title{
The effect of $C$. burnetii infection on the quality of life of patients following an outbreak of $Q$ fever
}

\author{
T. F. HATCHETTE ${ }^{1}$, M. HAYES ${ }^{2}$, H. MERRY ${ }^{1}$, W. F. SCHLECH ${ }^{1}$ \\ AND T. J. MARRIE ${ }^{3 *}$ \\ ${ }^{1}$ Queen Elizabeth II Health Sciences Centre, Dalhousie University, Halifax, Nova Scotia, Canada \\ ${ }^{2}$ Memorial University of Newfoundland, St. John's, Newfoundland, Canada \\ ${ }^{3}$ University of Alberta, 2F1.30 Walter C. Mackenzie Health Sciences Center, 8440112 St, Edmonton, Alberta, \\ T6H 2B7, Canada
}

(Accepted 6 January 2003)

\section{SUMMARY}

Sixty-six cases of Q fever were diagnosed in people affiliated with a goat-farming co-operative in rural Newfoundland in the spring of 1999. Follow-up studies which included administration of the Short Form 36 Health Survey (SF-36) were conducted 3 and 27 months after the initial outbreak to prospectively follow the effects of acute $\mathrm{Q}$ fever on the quality of life of the participants. Twenty-seven months after the outbreak $51 \%$ of those who had Q fever reported persistent symptoms including seven participants whose symptoms had initially resolved 3 months after the outbreak. Individuals with Q fever had significantly lower scores on five of the eight scales in the SF-36 and lower scores in the mental and physical summary scales compared to uninfected controls. Although this supports the hypothesis of a 'post Q fever fatigue syndrome' (QFFS), further study is warranted.

\section{INTRODUCTION}

$\mathrm{Q}$ fever is a worldwide zoonosis due to the obligate intracellular bacterium Coxiella burnetii [1]. This highly infectious pathogen has been isolated from many wild and domestic animals where it is shed in the milk, urine, feces, and is found in particularly high concentrations in the products of conception [2-7]. Human infection usually results from exposure to infected domestic ungulates or cats and may be asymptomatic or may manifest as pneumonia, hepatitis or a nonspecific febrile illness [8-12]. Most infections are self-limiting. However, chronic manifestations such as endocarditis, osteomyelitis and hepatitis have been well documented $[12,13]$. Although most patients suffering from acute $\mathrm{Q}$ fever have an 'uneventful' recovery, there is evidence that $C$. burnetii infection can

\footnotetext{
* Author for correspondence.
}

lead to a protracted state of fatigue similar to that seen with chronic fatigue syndrome [14-17]. Although the questionnaires used to measure fatigue by Marmion et al. [14] and Ayers et al. [15, 16] were similar, they were not widely standardized and correlation between healthy individuals or those with other chronic illness cannot be made.

In the spring of 1999 farmers and workers on a newly formed goat farm cooperative on a small rural peninsula in Newfoundland, Canada were diagnosed with Q fever. An epidemiological investigation revealed that $66 / 179(36.9 \%)$ farmers, workers and contacts had developed acute C. burnetii infection [11]. As part of the follow-up, we used the Medical Outcomes Study 36-item Short Form Health Survey (SF-36), a standardized quality of life instrument to prospectively follow members of this outbreak cohort to examine the impact of acute $\mathrm{Q}$ fever on the quality of life 3 months and 27 months after the initial diagnosis. 


\section{METHODS}

In the spring of 1999, serum samples and epidemiologic data were collected as part of an outbreak investigation of $\mathrm{Q}$ fever among workers belonging to a goat-farming co-operative in rural Newfoundland, at which time a diagnosis of $\mathrm{Q}$ fever was made serologically by indirect immunofluorescence as previously described [11]. In July 1999 (3 months after the original outbreak) the cohort was again contacted to participate in a follow-up investigation. A questionnaire was administered which consisted of two parts: questions regarding the nature and duration of persistent symptoms and the SF-36 quality-of-life measurement.

The SF-36 contains 36 items which measure different domains of participants health including: physical functioning (PF), role physical (RP), bodily pain $(\mathrm{BP})$, general health $(\mathrm{GH})$, vitality $(\mathrm{V})$, social functioning (SF), role emotion (RE), mental health $(\mathrm{MH})$ [18]. In addition the data generated can be further summarized into physical and mental scores. The domains are scored on a scale of 1-100, with lower scores reflecting poorer health [18]. This instrument has been well validated and found to be more responsive to changes in participants' health than other quality of life measures [18-20]. The SF-36 has been administered to healthy subjects as well as to individuals with a variety of illness to generate standardized data for comparison, including normative data for American, British, Australian and Canadian populations [18, 21-24]. The SF-36 Health Survey Scores of the outbreak cohort were compared with published Canadian normative data as well as standardized values from American patients with recent angina, and type 2 diabetes and British patients who report 'long standing illness' [18, 23, 24]. A second followup investigation was conducted in the summer of 2000 (27 months after the outbreak). Participants who filled out the first questionnaire in July 1999 were contacted and the same outcome measures were collected.

\section{Data analysis}

Participants were subgrouped in both studies based on whether they had C. burnetii infection during the outbreak, and whether they continued to report symptoms or whether their complaints had been resolved. Those who did not have Q fever were considered a control population to which the patients with $\mathrm{Q}$ fever were compared. Differences between infected and uninfected participants were tested for statistical
Table 1. Comparison of the SF-36 data between infected individuals and controls 3 months following the initial outbreak (July 1999)

\begin{tabular}{llll}
\hline \hline & $\begin{array}{l}\text { Q-fever } \\
(n=33)\end{array}$ & $\begin{array}{l}\text { No Q-fever } \\
(n=24)\end{array}$ & $P$ \\
\hline Bodily pain & $77 \cdot 3( \pm 26 \cdot 6)$ & $85 \cdot 3( \pm 18 \cdot 6)$ & $0 \cdot 3350$ \\
General health & $61 \cdot 8( \pm 26 \cdot 3)$ & $78 \cdot 0( \pm 15 \cdot 2)$ & $0 \cdot 0280$ \\
Mental health & $73 \cdot 9( \pm 22 \cdot 6)$ & $80 \cdot 5( \pm 15 \cdot 1)$ & $0 \cdot 3853$ \\
Physical function & $85 \cdot 6( \pm 19 \cdot 5)$ & $84 \cdot 7( \pm 25 \cdot 0)$ & $0 \cdot 4705$ \\
Role emotion & $77 \cdot 8( \pm 37 \cdot 0)$ & $95 \cdot 8( \pm 11 \cdot 3)$ & $0 \cdot 0509$ \\
Role physical & $72 \cdot 0( \pm 35 \cdot 2)$ & $87 \cdot 5( \pm 22 \cdot 1)$ & $0 \cdot 0763$ \\
Social function & $87 \cdot 5( \pm 22 \cdot 1)$ & $92 \cdot 7( \pm 14 \cdot 7)$ & $0 \cdot 4533$ \\
Vitality & $52 \cdot 7( \pm 30 \cdot 3)$ & $64 \cdot 4( \pm 24 \cdot 7)$ & $0 \cdot 1632$ \\
Physical scale & $48 \cdot 4( \pm 10 \cdot 3)$ & $50 \cdot 9( \pm 8 \cdot 7)$ & $0 \cdot 3685$ \\
Mental scale & $49 \cdot 1( \pm 12 \cdot 1)$ & $54 \cdot 3( \pm 6 \cdot 8)$ & $0 \cdot 2178$ \\
\hline \hline
\end{tabular}

Table 2. Comparison of the SF-36 data between infected individuals and controls 27 months after the initial outbreak (summer 2000)

\begin{tabular}{llll}
\hline \hline & $\begin{array}{l}\text { Q-fever } \\
(n=33)\end{array}$ & $\begin{array}{l}\text { No Q-fever } \\
(n=24)\end{array}$ & $P$ \\
\hline Bodily pain & $64 \cdot 6( \pm 29 \cdot 8)$ & $74 \cdot 0( \pm 27 \cdot 5)$ & $0 \cdot 2818$ \\
General health & $50 \cdot 5( \pm 27 \cdot 4)$ & $68 \cdot 7( \pm 19 \cdot 7)$ & $0 \cdot 0107$ \\
Mental health & $71 \cdot 5( \pm 18 \cdot 9)$ & $80 \cdot 0( \pm 16 \cdot 2)$ & $0 \cdot 1031$ \\
Physical function & $79 \cdot 4( \pm 20 \cdot 4)$ & $86 \cdot 2( \pm 23 \cdot 5)$ & $0 \cdot 0294$ \\
Role emotion & $70 \cdot 7( \pm 39 \cdot 8)$ & $87 \cdot 5( \pm 29 \cdot 2)$ & $0 \cdot 0800$ \\
Role physical & $51 \cdot 5( \pm 47 \cdot 2)$ & $84 \cdot 4( \pm 36 \cdot 0)$ & $0 \cdot 0064$ \\
Social function & $79 \cdot 5( \pm 21 \cdot 2)$ & $85 \cdot 9( \pm 26 \cdot 9)$ & $0 \cdot 0360$ \\
Vitality & $50 \cdot 3( \pm 23 \cdot 5)$ & $69 \cdot 6( \pm 23 \cdot 6)$ & $0 \cdot 0040$ \\
Physical scale & $42 \cdot 7( \pm 11 \cdot 3)$ & $49 \cdot 1( \pm 11 \cdot 5)$ & $0 \cdot 0175$ \\
Mental scale & $48 \cdot 2( \pm 10 \cdot 2)$ & $53 \cdot 2( \pm 8 \cdot 8)$ & $0 \cdot 0401$ \\
\hline \hline
\end{tabular}

significance using the $\chi^{2}$ test for proportions and Student's $t$-test for means. All data were analysed using SPSS for Windows version 8.0 (SPSS Inc. 1989-1999) and results were considered significant when $P<0.05$.

\section{RESULTS}

Although 82 members of the original outbreak cohort completed questionnaires during the July 1999 followup, only $57 / 179$ (32\%) of the original outbreak cohort completed the questionnaires at both the follow-ups in 1999 and 2001 and were used in the subsequent data analysis. The other members of the cohort could not be contacted or declined to participate in the study.

Of these 57 participants, $58 \%(33 / 57)$ had been diagnosed with acute $\mathrm{Q}$ fever during the original outbreak; $42 \%(24 / 57)$ did not have Q fever during 
Table 3. Comparison of the SF-36 data between infected individuals with persistent symptoms (FPS) and those participants whose symptoms resolved (FRS) 3 months after the initial outbreak (July 1999)

\begin{tabular}{llll}
\hline \hline & $\begin{array}{l}\text { QFPS } \\
(n=13)\end{array}$ & $\begin{array}{l}\text { QFRS } \\
(n=13)\end{array}$ & $P$ \\
\hline Bodily pain & $62 \cdot 9( \pm 31 \cdot 8)$ & $86 \cdot 3( \pm 16 \cdot 4)$ & $0 \cdot 0577$ \\
General health & $43 \cdot 9( \pm 25 \cdot 7)$ & $70 \cdot 5( \pm 20 \cdot 9)$ & $0 \cdot 0204$ \\
Mental health & $57 \cdot 2( \pm 23 \cdot 3)$ & $85 \cdot 2( \pm 15 \cdot 0)$ & $0 \cdot 0042$ \\
Physical function & $75 \cdot 8( \pm 20 \cdot 2)$ & $90 \cdot 0( \pm 20 \cdot 0)$ & $0 \cdot 0639$ \\
Role emotion & $56 \cdot 4( \pm 43 \cdot 9)$ & $94 \cdot 9( \pm 12 \cdot 5)$ & $0 \cdot 0104$ \\
Role physical & $50 \cdot 0( \pm 40 \cdot 8)$ & $84 \cdot 6( \pm 24 \cdot 0)$ & $0 \cdot 0206$ \\
Social function & $73 \cdot 1( \pm 28 \cdot 8)$ & $97 \cdot 1( \pm 7 \cdot 5)$ & $0 \cdot 0099$ \\
Vitality & $29 \cdot 2( \pm 24 \cdot 8)$ & $64 \cdot 6( \pm 22 \cdot 1)$ & $0 \cdot 0014$ \\
Physical scale & $43 \cdot 1( \pm 10 \cdot 9)$ & $50 \cdot 6( \pm 10 \cdot 2)$ & $0 \cdot 0455$ \\
Mental scale & $39 \cdot 9( \pm 12 \cdot 4)$ & $55 \cdot 5( \pm 5 \cdot 8)$ & $0 \cdot 0015$ \\
\hline \hline
\end{tabular}

Table 4. Comparison of the SF-36 data between infected individuals with persistent symptoms and those participants whose symptoms resolved 27 months after the initial outbreak (summer 2000)

\begin{tabular}{llll}
\hline \hline & $\begin{array}{l}\text { QFPS } \\
(n=17)\end{array}$ & $\begin{array}{l}\text { QFRS } \\
(n=9)\end{array}$ & $P$ \\
\hline Bodily pain & $55 \cdot 1( \pm 26 \cdot 1)$ & $73 \cdot 2( \pm 32 \cdot 2)$ & $0 \cdot 1346$ \\
General health & $34 \cdot 1( \pm 21 \cdot 3)$ & $63 \cdot 2( \pm 22 \cdot 7)$ & $0 \cdot 0102$ \\
Mental health & $61 \cdot 9( \pm 16 \cdot 9)$ & $76 \cdot 9( \pm 14 \cdot 4)$ & $0 \cdot 0399$ \\
Physical function & $71 \cdot 8( \pm 21 \cdot 9)$ & $83 \cdot 3( \pm 19 \cdot 2)$ & $0 \cdot 1503$ \\
Role emotion & $52 \cdot 9( \pm 42 \cdot 6)$ & $81 \cdot 5( \pm 33 \cdot 8)$ & $0 \cdot 1019$ \\
Role physical & $35 \cdot 3( \pm 44 \cdot 2)$ & $66 \cdot 7( \pm 45 \cdot 1)$ & $0 \cdot 1430$ \\
Social function & $75 \cdot 0( \pm 22 \cdot 1)$ & $83 \cdot 3( \pm 15 \cdot 3)$ & $0 \cdot 3914$ \\
Vitality & $37 \cdot 9( \pm 17 \cdot 9)$ & $60 \cdot 0( \pm 17 \cdot 3)$ & $0 \cdot 0095$ \\
Physical scale & $38 \cdot 4( \pm 9 \cdot 0)$ & $46 \cdot 6( \pm 12 \cdot 6)$ & $0 \cdot 0311$ \\
Mental scale & $43 \cdot 2( \pm 10 \cdot 0)$ & $51 \cdot 2( \pm 8 \cdot 4)$ & $0 \cdot 0592$ \\
\hline \hline
\end{tabular}

the outbreak and were used as controls. The results of the SF-36 data are presented in Tables 1-5.

Only the general health scores reported by the Q fever group were significantly different from the control group at the first follow up investigation 3 months after the outbreak $(61 \cdot 8 v s .78 \cdot 0 ; P=0.03)$. However 27 months after the original outbreak, participants with Q fever had significantly lower scores on five of the eight scales and the physical and mental summary scales.

Participants with Q fever could be subgrouped based on whether they continued to report symptoms they attributed to $C$. burnetii infection, whether their initial symptoms had resolved, or whether they never had symptoms at the time of the outbreak (Tables 3-5). Three months after the outbreak, 39\% (13/33) of participants with $C$. burnetii infection continued to report symptoms and had significantly lower scores on all scales except for physical function compared to $39 \%(13 / 33)$ of the infected participants whose symptoms had resolved.

Twenty-seven months after the initial outbreak $52 \%(17 / 33)$ of the participants who had Q fever continued to report persistent symptoms. Three participants who originally had persistent symptoms had resolution of their symptoms 27 months after the outbreak. In contrast seven participants with Q fever whose symptoms initially resolved 3 months after the outbreak developed persistent symptoms they attributed to Q fever 27 months after the outbreak. Only the scores in the general health, mental health, vitality and the physical summary scales were lower in participants with persistent symptoms compared with those whose symptoms resolved. This may be a reflection of the lower scores on all scales of the SF-36 survey including the physical and mental summary

Table 5. Changes in mental and physical summary scales for $Q$ fever patients and control participants between July 1999 and Summer 2000

\begin{tabular}{lllll}
\hline \hline & $\begin{array}{l}\text { Controls } \\
(n=24)\end{array}$ & $P$ & $\begin{array}{l}\text { Q-fever group } \\
(n=33)\end{array}$ & $P$ \\
\hline Bodily pain & $-11 \cdot 2( \pm 19 \cdot 7)$ & $0 \cdot 0108$ & $-12 \cdot 8( \pm 29 \cdot 2)$ & $0 \cdot 0162$ \\
General health & $-9 \cdot 2( \pm 17 \cdot 7)$ & $0 \cdot 0066$ & $-11 \cdot 3( \pm 21 \cdot 5)$ & $0 \cdot 0059$ \\
Mental health & $-0 \cdot 5( \pm 13 \cdot 7)$ & $0 \cdot 5627$ & $-2 \cdot 4( \pm 17 \cdot 7)$ & $0 \cdot 4095$ \\
Physical function & $1 \cdot 6( \pm 22 \cdot 0)$ & $0 \cdot 8379$ & $-6 \cdot 2( \pm 13 \cdot 7)$ & $0 \cdot 0093$ \\
Role emotion & $-8 \cdot 3( \pm 28 \cdot 2)$ & $0 \cdot 2656$ & $-7 \cdot 1( \pm 51 \cdot 2)$ & $0 \cdot 3965$ \\
Role physical & $-3 \cdot 1( \pm 23 \cdot 7)$ & $0 \cdot 6719$ & $-20 \cdot 5(43 \cdot 1)$ & $0 \cdot 0097$ \\
Social function & $-6 \cdot 8( \pm 24 \cdot 4)$ & $0 \cdot 3623$ & $-8 \cdot 0( \pm 27 \cdot 9)$ & $0 \cdot 1823$ \\
Vitality & $5 \cdot 2( \pm 17 \cdot 1)$ & $0 \cdot 0198$ & $-2 \cdot 4( \pm 28 \cdot 6)$ & $0 \cdot 7071$ \\
Physical scale & $-1 \cdot 9( \pm 8 \cdot 0)$ & $0 \cdot 2083$ & $-5 \cdot 7( \pm 10 \cdot 0)$ & $0 \cdot 0021$ \\
Mental scale & $-1 \cdot 3( \pm 8 \cdot 1)$ & $0 \cdot 4022$ & $-0 \cdot 8( \pm 12 \cdot 9)$ & $0 \cdot 7071$ \\
\hline \hline
\end{tabular}


scores recorded by both participants with Q fever and controls (Table 5). Although there was a slight increase in the physical function scores and a significant $(P=0.02)$ increase in vitality scores in the control group between the two time periods, the remainder of the scales in both groups, including the physical and mental summaries were lower, with significant decreases in the bodily pain and general health scales $(P=0.01 ; P=0 \cdot 007)$.

There were no initial symptoms that were predictive of developing persistent symptoms after acute $\mathrm{Q}$ fever. Antibiotic treatment at the time of acute infection was not predictive of the development of persistent symptoms. There was no obvious source of exposure that was associated with developing persistent symptoms.

\section{DISCUSSION}

The Q fever fatigue syndrome (QFFS) has been proposed to describe the protracted state of fatigue that can develop in $20 \%$ of patients who develop acute infection with $C$. burnetii [14-16]. First described in Australian abattoir workers, QFFS consists of symptoms including fatigue, headaches, sweats, arthralgias, myalgias, blurred vision, muscle fasciculations and enlarged and painful lymph nodes [14]. Subsequent studies in the United Kingdom have also supported the existence of QFFS $[15,16]$. In a case-control study 5 years after a large outbreak of Q fever, Ayres et al. found that participants who were diagnosed with acute $\mathrm{Q}$ fever during the initial outbreak had more complaints of fatigue, sweats, blurring of vision and dyspnoea than their matched controls and that $42 \cdot 3 \%$ of the infected individuals actually fulfilled the CDC criteria for chronic fatigue state [16]. In a 10-year follow-up of the same cohort Wildman et al. found that $64.8 \%$ of $\mathrm{Q}$ fever exposed participants had fatigue and $34.4 \%$ fulfilled the criteria for chronic fatigue syndrome, both of which were significantly higher than that seen in matched controls [17]. Although not conclusive, there is evidence to suggest that 'cytokine dysregulation and immunomodulation from persistence of $C$. burnetii' in the host may be responsible for QFFS [25, 26].

The data presented in the current study suggest that individuals infected with $\mathrm{Q}$ fever can have persistent symptoms $>2$ years after an acute outbreak, which has significant impact on their quality of life similar to British residents who report long standing illness [23] and Americans with other chronic maladies such as, type 2 diabetes mellitus, active coronary artery disease [18]. Compared to the published normalized Canadian data [24], the control 'normal' population did not differ except for higher bodily pain (BP) $(P=0 \cdot 04)$ on the July 1999 survey and lower score on the mental health (MH) scale $(P=0.04)$ on the summer 2001 survey, suggesting that the members of this cohort function as well as the average Canadian and American and that the lower values seen in those individuals with $\mathrm{Q}$ fever who have persistent symptoms are not biased by lower 'normal' values.

This study has a number of limitations that should be considered when interpreting the results, including poor follow-up survey participation, and a potential participation bias that individuals who continued to have symptoms were more likely to participate in the study. In addition data on other co-morbidities were not available and may have impacted on the SF-36 scores reported in both the infected and uninfected cohorts. Follow-up serological data to ensure that none of the participants had serological evidence of chronic Q fever was incomplete and the statistical power of the study is limited by the low number of participants. Additional confounding variables may include socioeconomic factors. The farming cooperative was the main source of income for many of the participants and the Q fever outbreak contributed to the dissolution of the cooperative and farm closures, leaving many people without employment.

The existence of a $\mathrm{Q}$ fever fatigue syndrome is controversial and is difficult to prove conclusively. Wildman et al. admit that their results 'may not represent fatigue at all, but represent a biased response to questionnaires caused by the process of follow up' [17]. Although the data presented here reflect further evidence of the existence of a QFFS, the possibility that these differences reflect the socioeconomic, physiologic or psychological effects of being labelled with the diagnosis of $\mathrm{Q}$ fever rather than true post-infectious sequalae cannot be excluded and warrants further study.

\section{ACKNOWLEDGEMENTS}

This research was funded by a grant from the Queen Elizabeth II Health Science Center Research Foundation.

\section{REFERENCES}

1. Kaplan MM, Bertagna P. The geographical distribution of Q fever. Bull WHO 1955; 13: 829-60. 
2. Marrie TJ, VanBuren J, Fraser J, et al. Seroepidemiology of Q fever among domestic animals in Nova Scotia. Am J Public Health 1985; 75: 763-6.

3. Marrie TJ, Embil J, Yates L. Seroepidemiology of Coxiella burnetii among wildlife in Nova Scotia. Am J Trop Med Hyg 1993; 49: 613-5.

4. Moore JD, Barr BC, Daft BM, et al. Pathology and diagnosis of Coxiella burnetii infection in a goat herd. Vet Pathol 1991; 28: 81-4.

5. Abinanti FR, Lennette EH, Winn JF, et al. XVVII. Presence of Coxiella burnetii in the birth fluids of naturally infected sheep. Am J Hyg $1953 ;$ 58: 358-88.

6. Tigertt WD, Benenson AS, Gochenour WS. Airborne Q fever. Bacteriol Rev 1961; 25: 285-93.

7. Ormsbee R, Peacock M, Gerloff R, et al. Limits of rickettsial infectivity. Infect Immun 1978; 19: 239-45.

8. Luoto L, Pickens EG. A resume of recent research seeking to define the Q-fever problem. Am J Hyg 1961; 74: 43-9.

9. Dupuis G, Petite J, Peter O, et al. An important outbreak of human Q fever in a Swiss alpine valley. Inter J Epidemiol 1987; 16: 282-7.

10. Marrie TJ, Durant H, Williams JC, Mintz E, Waag DM. Exposure to parturient cats: a risk factor for acquisition of Q fever in Maritime Canada. J Infect Dis 1988; 158: 101-8.

11. Hatchette TF, Hudson RC, Schlech WF, et al. Goat associated Q fever: a new disease in Newfoundland. Emerg Infect Dis 2001; 7: 413-9.

12. Tissot Dupont H, Raoult D, Brouqui P, et al. Epidemiologic features and clinical presentation of acute Q fever in hospitalised patients : 323 French cases. Am J Med 1992; 93: 427-34.

13. Raoult D, Tissont-Dupont H, Foucault C, et al. Q fever 1985-1998. Clinical and epidemiologic features of 1383 infections. Medicine 2000; 79: 109-23.

14. Ayres JG, Smith EG, Flint N. Protracted fatigue and debility after acute Q fever. Lancet 1996; 347: 978-9.

15. Marmion BP, Shannon M, Maddocks I, Storm P, Penttila I. Protracted debility and fatigue after acute Q fever. Lancet 1996; 347: 977-8.
16. Ayres JG, Flint N, Smith EG, et al. Post infection fatigue syndrome following Q fever. Q J Med 1998; 91 : 105-23.

17. Wildman MJ, Smith EG, Groves J, Beattie JM, Caul EO, Ayres JG. Chronic fatigue following infection by Coxiella burnetii ( $\mathrm{Q}$ fever): ten-year follow-up of the 1989 UK outbreak cohort. Q J Med 2002; 95: 527-38.

18. Ware JE. SF-36 Health Survey Manual and interpretation guide. Boston, The Health Institute, New England Medical Center, 1990.

19. Beaton DE, Hogg-Johnson S, Bombardier C. Evaluating changes in health status: reliability and responsiveness of five generic health status measures in workers with musculoskeletal disorders. J Clin Epidemiol 1997; 50: 79-93.

20. Essink-Bot ML, Krabbe PFM, Bonsel GJ, Aaronson NK. An empirical comparison of four generic health status measures. Med Care 1997; 35: 522-37.

21. Jenkinson C, Coulter C, Wright L. Short Form 36 (SF-36) Health Survey questionnaire: normative data for adults of working age. BMJ 1993; 306: 1437-40.

22. Watson EK, Firman DW, Baade PD, Ring I. Telephone administration of the SF-36 Health Survey: validation studies and population norms for adults in Queensland. Aust N Z J Public Health 1996; 20: 359-63.

23. Jenkinson $\mathrm{C}$, Stewart-Brown S, Petersen S, Paice C. Assessment of the SF-36 version 2 in the United Kingdom. J Epidemiol Commun Health 1999; 53: 46-50.

24. Hopman WM, Towheed T, Anastassiades T, et al. Canadian normative data for the SF-36 health survey. CMAJ 2000; 163: 265-71.

25. Penttila IA, Harris RJ, Storm P, Haynes D, Worswick DA, Marmion BP. Cytokine dysregulation in the post-Q fever fatigue syndrome. Q J Med 1998; 91 : 549-60.

26. Harris RJ, Storm PA, Lloyd A, Arens M, Marmion BP. Long-term persistence of Coxiella burnetii in the host after primary Q fever. Epidemiol Infect 2000; 124: 543-9. 